OPEN ACCESS

Edited by:

Kamlesh Jangid,

National Centre for Cell Science

(NCCS), India

Reviewed by:

Nagendran Tharmalingam,

Alpert Medical School, United States

Dane Parker,

Columbia University, United States

*Correspondence:

Jae G. Park

jaepark@pohangtp.org

Jintae Lee

jtlee@ynu.ac.kr

tThese authors have contributed equally to this work.

Specialty section:

This article was submitted to Antimicrobials, Resistance and Chemotherapy,

a section of the journal

Frontiers in Microbiology

Received: 20 February 2018

Accepted: 23 May 2018

Published: 15 June 2018

Citation:

Kim Y-G, Lee J-H, Raorane CJ,

Oh ST, Park JG and Lee J (2018)

Herring Oil and Omega Fatty Acids Inhibit Staphylococcus aureus Biofilm

Formation and Virulence.

Front. Microbiol. 9:1241.

doi: 10.3389/fmicb.2018.01241

\section{Herring Oil and Omega Fatty Acids Inhibit Staphylococcus aureus Biofilm Formation and Virulence}

\author{
Yong-Guy Kim ${ }^{1 \dagger}$, Jin-Hyung Lee ${ }^{1 t}$, Chaitany J. Raorane ${ }^{1}$, Seong T. Oh², Jae G. Park ${ }^{3 *}$ \\ and Jintae Lee ${ }^{1 *}$ \\ 1 School of Chemical Engineering, Yeungnam University, Gyeongsan, South Korea, ${ }^{2}$ College of Pharmacy, Yeungnam \\ University, Gyeongsan, South Korea, ${ }^{3}$ Advanced Bio Convergence Center, Pohang Technopark Foundation, Pohang, \\ South Korea
}

Staphylococcus aureus is notorious for its ability to become resistant to antibiotics and biofilms play a critical role in antibiotic tolerance. S. aureus is also capable of secreting several exotoxins associated with the pathogenesis of sepsis and pneumonia. Thus, the objectives of the study were to examine S. aureus biofilm formation in vitro, and the effects of herring oil and its main components, omega fatty acids [cis4,7,10,13,16,19-docosahexaenoic acid (DHA) and cis-5,8,11,14,17-eicosapentaenoic acid (EPA)], on virulence factor production and transcriptional changes in $S$. aureus. Herring oil decreased biofilm formation by two S. aureus strains. GC-MS analysis revealed the presence of several polyunsaturated fatty acids in herring oil, and of these, two omega-3 fatty acids, DHA and EPA, significantly inhibited S. aureus biofilm formation. In addition, herring oil, DHA, and EPA at $20 \mu \mathrm{g} / \mathrm{ml}$ significantly decreased the hemolytic effect of $S$. aureus on human red blood cells, and when pre-treated to S. aureus, the bacterium was more easily killed by human whole blood. Transcriptional analysis showed that herring oil, DHA, and EPA repressed the expression of the $\alpha$-hemolysin hla gene. Furthermore, in a Caenorhabditis elegans nematode model, all three prolonged nematode survival in the presence of $S$. aureus. These findings suggest that herring oil, DHA, and EPA are potentially useful for controlling persistent $S$. aureus infection.

Keywords: biofilm, hemolysis, herring oil, omega fatty acids, Staphylococcus aureus, virulence

\section{INTRODUCTION}

The sticky conglomerations of bacteria that adhere to diverse medical devices or damaged body tissues can become causes of persistent infections. These bacteria encase themselves in a slime layer or biofilm, which poses serious problems to human health because of their abilities to tolerate conventional antibiotic chemotherapies, host immune systems, and external stresses (Potera, 1999; Hoffman et al., 2005).

Staphylococcus aureus is an important etiologic agent and a major cause of a diverse array of acute life-threatening bloodstream infections in man, and is often held responsible for worldwide outbreaks of nosocomial infections (Lowy, 1998). S. aureus biofilms play a critical role in antibiotic tolerance (Stewart and Costerton, 2001), and methicillin-resistant S. aureus (MRSA) and vancomycin-resistant $S$. aureus have become major nosocomial threats 
(Speller et al., 1997). S. aureus secretes many exotoxins, including coagulase, enterotoxins, $\alpha$-hemolysin, protein A, and TSST1, which damage biological membranes and eventually cause cell death (Ohlsen et al., 1997; Otto, 2014). Also, S. aureus biofilms are found in medical devices and food surfaces, and are responsible for food-poisoning and toxic shock syndrome (Chambers and Deleo, 2009). In particular, $\alpha$-hemolysin (Hla) is a major cytotoxic agent that has been associated with the pathogeneses of pneumonia, sepsis, and severe skin infections (Menzies and Kernodle, 1996; Wilke and Bubeck Wardenburg, 2010) and with biofilm formation (Caiazza and O'Toole, 2003). S. aureus biofilms also play a dominant role in the determination of disease severity and postoperative course (Singhal et al., 2011). Therefore, it is important to find means to inhibit biofilm formation and the virulent characteristics of S. aureus. For this purpose, novel and non-toxic compounds that prevent the development of drug tolerance are urgently required.

Semi-dried raw Pacific herring (Clupea pallasi), also known as Gwamegi (a Korean traditional food), is an important fishery product with a unique flavor, taste, and texture (Lee et al., 2002; Kang et al., 2011). Herring oil contains an abundance of two rare omega-3 polyunsaturated fatty acids (PUFAs), namely, docosahexaenoic acid (DHA; C22:6, $\omega$-3) and eicosapentaenoic acid (EPA; C20:5, $\omega-3$ ), which are commonly present at low concentrations in non-marine animals and are beneficial to the human body (Hirai et al., 1980; Schmidt and Dyerberg, 1994). Furthermore, it has been reported that two PUFAs act as bacteriocides on Gram-positive and Gram-negative bacteria, such as, Helicobacter pylori (Correia et al., 2012), Burkholderia cenocepacia (Mil-Homens et al., 2012), S. aureus (Desbois et al., 2009), Fusobacterium nucleatum, Porphyromonas gingivalis, and Streptococcus mutans (Huang and Ebersole, 2010; Sun et al., 2016, 2017). These two PUFAs have also been reported to possess significant anti-inflammatory, antitumorigenic (Bougnoux, 1999; Van Dyke, 2008), and antioxidant activities (Giordano and Visioli, 2014). Huang and Ebersole (2010), Sun et al. (2016, 2017) and Thibane et al. (2010) suggested that DHA and EPA could be considered as potential supplementary therapeutic agents due to their anti-biofilm activities on Candida species and periodontopathic bacteria. However, the abilities of DHA and EPA to inhibit biofilm formation and virulence production by $S$. aureus have not been assessed.

Therefore, the phenotypic effects of herring oil were studied and its active constituents were identified by gas chromatography-mass spectrometry (GC-MS). Two of its major constituents (DHA and EPA) were further investigated by confocal laser scanning microscopy (CSLM) and using a human blood assay to determine their effects on biofilm formation and toxin production by $S$. aureus. A Caenorhabditis elegans model was used to investigate the anti-virulent properties of herring oil, DHA, and EPA. qRT-PCR (quantitative realtime reverse transcription polymerase chain reaction) was used to investigate their effects on the transcriptional profiles of genes related to biofilm formation and virulence production in vitro.

\section{MATERIALS AND METHODS}

\section{Ethics Statement}

Human blood assays were authorized by the Ethical Committee of Yeungnam University (Gyeongsan, South Korea). The study was conducted according to the guidelines issued by the Ethical Committee of Yeungnam University. All blood donors provided written consent before blood collection.

\section{Bacterial Strains, Materials, and Growth Assay}

A methicillin-sensitive S. aureus strain (MSSA; ATCC 6538) and a methicillin-resistant $S$. aureus strain (MRSA; ATCC 33591) were used in the present study. All experiments were conducted at $37^{\circ} \mathrm{C}$ in Luria-Bertani (LB) broth for the MSSA strain and in LB broth containing $0.2 \%$ glucose for the MRSA strain. Herring (Clupea pallasii) oil was prepared from semi-dried fish bodies without organs (so called Gwamegi, Korean traditional food). Herring was dried at open air condition for 20 days in winter at Pohang, Korea. The semi-dried herring (764 g) was further dried in a freezing drier for 3 days to gain $586 \mathrm{~g}$ of dried herring. Then it was chopped, and the oil was extracted by soxhlet apparatus that was refluxed with n-hexane for a day at $70^{\circ} \mathrm{C}$. After refluxing, the residual solution was collected and washed with $1 \% \mathrm{AcOH}$ solution and brine to remove excess protein. Washed oil was dried over anhydrous $\mathrm{MgSO}_{4}$ to gain clear yellow viscous oil (267 g, 45.6\% yield). The omega fatty acids (cis-4,7,10,13,16,19-DHA, cis-5,8,11,14,17-EPA, cis-11-eicosenoic acid, and erucic acid), crystal violet, ethanol, ciprofloxacin, vancomycin and glucose were purchased from Sigma-Aldrich (St. Louis, MO, United States). For cell growth assays, optical densities were measured at $600 \mathrm{~nm}$ using a spectrophotometer (Optizen 2120UV, Mecasys, South Korea). To determine MIC (minimum inhibitory concentration), cells were inoculated into LB broth and cultured overnight at a dilution of $1: 100$ at $37^{\circ} \mathrm{C}$, and then incubated for $24 \mathrm{~h}$ in the presence of a test substance. After sequential dilutions, cultures were spread on LB agar plates, incubated for $24 \mathrm{~h}$ at $37^{\circ} \mathrm{C}$, and numbers of colonies were counted. Each experiment was performed using at least four independent cultures.

\section{Gas Chromatograph/Mass Spectroscopy (GC-MS)}

The chemical composition of air-dried herring oil was determined by GC using an Agilent 6890N GC and SP-2560 (Supelco, Sigma-Aldrich, St. Louis, MO, United States) fused silica capillary column $(100 \mathrm{~m} \times 0.25 \mathrm{~mm}$ i.d., film thickness $0.25 \mu \mathrm{m})$. Capillary column details, temperature conditions, and the derivatization (methylation) of fatty acids were as previously described (Lee et al., 2017). In brief, helium was used as the carrier at $0.75 \mathrm{ml} / \mathrm{min}$ and the GC injector was held at $225^{\circ} \mathrm{C}$. The GC oven temperature was programmed as follows; $100^{\circ} \mathrm{C}$ for $4 \mathrm{~min}$, increased to $240^{\circ} \mathrm{C}$ at $3^{\circ} \mathrm{C} / \mathrm{min}$, and followed by $15 \mathrm{~min}$ at $250^{\circ} \mathrm{C}$. The split ratio was controlled at 200:1. Triundecanoin $\left(\mathrm{C}_{11: 00}\right)$ was used as the internal standard and quantifications were performed by integrating areas and correcting for fatty acid 
A

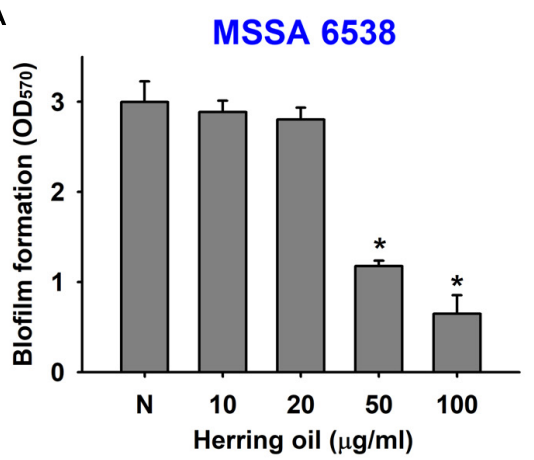

C

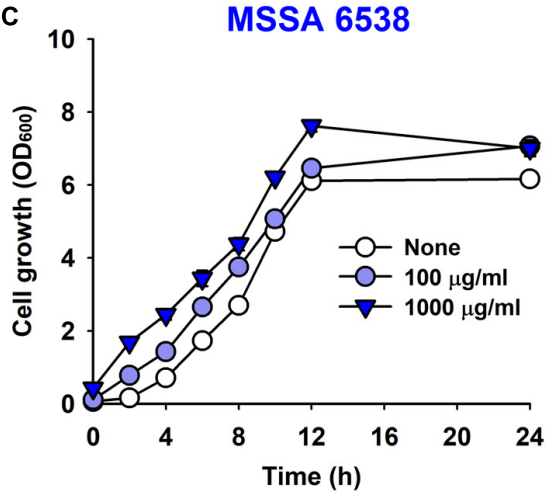

B

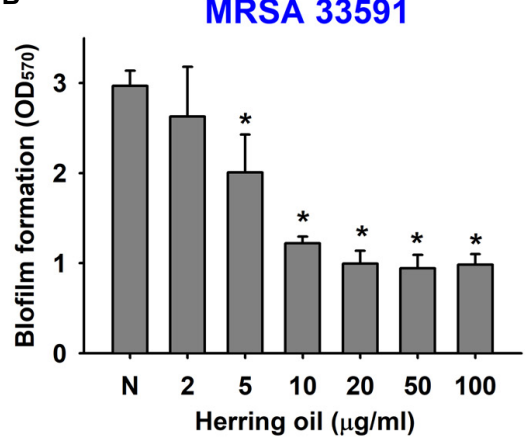

D MRSA 33591

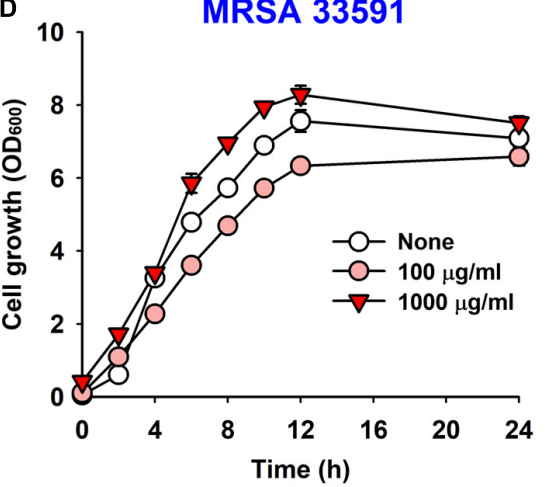

FIGURE 1 | Effects of herring oil on biofilm formation by Staphylococcus aureus strains and on their antimicrobial activities. S. aureus (MSSA 6538 or MRSA 33591 ) biofilm formations $\left(\mathrm{OD}_{570}\right)$ were quantified in the presence of herring oil for $24 \mathrm{~h}$ in 96 -well polystyrene plates $(\mathbf{A}, \mathbf{B})$. Planktonic cell growths $\left(O D_{600}\right)$ of $S$. aureus cells (MSSA 6538 and MRSA 33591) were measured in the presence of herring oil in $250 \mathrm{ml}$ flasks agitated at $250 \mathrm{rpm}$ (C,D). * $p<0.05$ vs. non-treated controls.

methylation. Supelco 37 components FAME Mix (Supelco) were used as the reference standard.

\section{Crystal-Violet Biofilm Assay}

The two bacterial strains (MSSA 6538, MRSA 33591) were subjected to a static biofilm formation assay on 96-well polystyrene plates (SPL Life Sciences, South Korea), as previously described (Kim et al., 2015). Briefly, cells were inoculated into LB broth $(300 \mu \mathrm{l})$ at an initial turbidity of 0.05 at $600 \mathrm{~nm}$ and herring oil, cis-11-eicosenoic acid, DHA, EPA, or erucic acid were added at different concentrations and incubated for $24 \mathrm{~h}$ without shaking at $37^{\circ} \mathrm{C}$. To quantify biofilm formation, cell cultures were washed three times with water and then biofilms were stained with $0.1 \%$ crystal violet for $20 \mathrm{~min}$. Biofilms were then dissolved in $300 \mu \mathrm{l}$ of $95 \%$ ethanol and absorbances were measured at $570 \mathrm{~nm}\left(\mathrm{OD}_{570}\right)$. For the biofilm dispersion assay, S. aureus was cultured in 96 -well plates for $24 \mathrm{~h}$ without shaking at $37^{\circ} \mathrm{C}$. Then, herring oil, DHA, or EPA was added to the cultures and incubated for another $10 \mathrm{~h}$ before the biofilm assay. Static biofilm formation results are the averages of four independent cultures of twelve replicate wells.

\section{Confocal Laser Scanning Microscopy and COMSTAT Analysis}

Static biofilm formation by S. aureus (MSSA 6538) in 96-well plates (without shaking) in the presence or absence of herring oil, DHA, or EPA were assessed by confocal laser scanning microscopy (Nikon Eclipse Ti, Tokyo, Japan). Cells were stained with carboxyfluorescein diacetate succinimidyl ester (Invitrogen, Molecular Probes Inc., Eugene, OR, United States), which stains viable cells in biofilms, as previously reported (Lee et al., 2016). Stained S. aureus ATCC 6538 biofilms were visualized by confocal laser scanning microscopy using an Ar laser (excitation wavelength $488 \mathrm{~nm}$, and emission wavelength 500-550 nm) and a $20 \times$ objective. Color confocal images were constructed using NIS-Elements $C$ version 3.2 (Nikon eclipse) under the same conditions. For each experiment, at least 10 random positions in two independent cultures were observed, and 20 planar images were analyzed per position. To quantify biofilm formation, COMSTAT biofilm software (Heydorn et al., 2000) was used to measure biovolumes $\left(\mu \mathrm{m}^{3}\right.$ per $\left.\mu \mathrm{m}^{2}\right)$, mean thicknesses $(\mu \mathrm{m})$, and substratum coverages (\%). Thresholds were fixed for all image stacks, and at least 4 positions and 20 planar images were analyzed per position.

\section{Hemolysis Assay}

Human red blood cell hemolysis efficacies were assayed using whole cultures of $S$. aureus, as described previously (Lee et al., 2013; Tharmalingam et al., 2018). Briefly, S. aureus cells (MSSA 6538) were diluted $1: 100$ in LB broth $\left(9 \times 10^{9} \mathrm{CFU} / \mathrm{ml}\right)$ with overnight culture and incubated with or without herring oil, DHA, or EPA for $20 \mathrm{~h}$ with shaking at $250 \mathrm{rpm}$. Separately, 
human whole blood samples were centrifuged at $900 \mathrm{~g}$ for $2 \mathrm{~min}$ and then washed three times with PBS and diluted in PBS (330 $\mu \mathrm{l}$ of red blood cells per $10 \mathrm{ml}$ of PBS buffer). Bacterial culture $(200 \mu \mathrm{l})$ was then added to $1 \mathrm{ml}$ of diluted human red blood cells (3.3\% in PBS). To determine hemolytic activities, mixtures of blood and $S$. aureus were incubated at $250 \mathrm{rpm}$ for $2 \mathrm{~h}$ at $37^{\circ} \mathrm{C}$. Supernatants were collected by centrifugation at $16,600 \mathrm{~g}$ for $10 \mathrm{~min}$ and optical densities were measured at $543 \mathrm{~nm}$.

\section{Whole Blood Bacterial Cell Killing Assay}

The whole blood cell killing assay used was as previously described (Liu et al., 2008). Briefly, S. aureus (MSSA 6538) cells were inoculated (1:100 dilution, $\left.\mathrm{OD}_{600} \sim 0.05\right)$ in LB broth with overnight culture and incubated at $37^{\circ} \mathrm{C}$ for $20 \mathrm{~h}$ with shaking at $250 \mathrm{rpm}$ with herring oil, DHA, or $\operatorname{EPA}(1,5$, or $20 \mu \mathrm{g} / \mathrm{ml})$ or DMSO (the negative control). Freshly drawn human whole blood $(0.3 \mathrm{ml})$ was then mixed with the $S$. aureus cultures $(0.1 \mathrm{ml})$, and mixtures were incubated at $37^{\circ} \mathrm{C}$ for $3 \mathrm{~h}$ with shaking at $250 \mathrm{rpm}$. S. aureus (MSSA 6538) survival was measured by counting CFUs on LB agar plates.

\section{Caenorhabditis elegans Survival Assay}

To investigate the effects of herring oil and unsaturated fatty acids on the virulence of $S$. aureus MSSA 6538, we used a nematode survival assay as previously described (Kim et al., 2016) with slight modification. In brief, S. aureus cells were incubated with or without herring oil, DHA, or EPA $(2,5$, or $20 \mu \mathrm{g} / \mathrm{ml}$ ) at $37^{\circ} \mathrm{C}$ for $24 \mathrm{~h}$ and synchronized adult C. elegans fer-15;fem-1 nematodes were added into single wells of 96-well plate containing cultivated $S$. aureus cells. Approximately, 30 nematodes were allowed to feed on the cultured $S$. aureus MSSA 6538 at $25^{\circ} \mathrm{C}$ for 1 day.

For the cytotoxicity assay, $110 \pm 10$ nematodes were added into single well of 96-well plates containing M9 buffer and solutions of the compounds were added to final concentrations of 20 or $100 \mu \mathrm{g} / \mathrm{ml}$ at $25^{\circ} \mathrm{C}$ for 1 day. Then, nematodes were scored as alive or dead using an $\mathrm{iRiS}^{\mathrm{TM}}$ Digital Cell Imaging System (Logos Bio Systems, South Korea). At least three independent experiments were conducted using quadruplicate wells.

\section{RNA Isolation and qRT-PCR}

Staphylococcus aureus MSSA 6538 cells were inoculated into $25 \mathrm{ml}$ of $\mathrm{LB}$ broth at $37^{\circ} \mathrm{C}$ in $250 \mathrm{ml}$ flasks at a starting $\mathrm{OD}_{600}$ of 0.05 , and then incubated for $5 \mathrm{~h}$ with shaking at $250 \mathrm{rpm}$ in the presence or absence of herring oil (100 $\mu \mathrm{g} / \mathrm{ml})$, DHA, or EPA $(20 \mu \mathrm{g} / \mathrm{ml})$. RNase inhibitor (RNAlater, Ambion, TX, United States) was then added and cells were immediately chilled for $30 \mathrm{~s}$ in dry ice bath having 95\% ethanol to prevent RNA degradation. Cells were then harvested by centrifugation at $16,600 \mathrm{~g}$ for $1 \mathrm{~min}$ and total RNA was isolated using a Qiagen RNeasy mini Kit (Valencia, CA, United States).

Quantitative real-time reverse transcription polymerase chain reaction was used to investigate the transcriptional levels of 10 biofilm-related genes, that are, agrA, arlR, arlS, aur, hla, icaA, nuc1, rbf, RNAIII, saeR, sarA, sarZ, seb, sigB, and spa in S. aureus
MSSA 6538 cells. Gene specific primers were used and 16s rRNA was used as the housekeeping control (Supplementary Table S1) to normalize the expressions of genes of interest. The qRTPCR technique employed was an adaptation of a previously described method (Lee et al., 2016). qRT-PCR was performed using a SYBR Green master mix (Applied Biosystems, Foster City, CA, United States) and an ABI StepOne Real-Time PCR System (Applied Biosystems). Expression levels were determined using two independent cultures and six qRT-PCR reactions per gene.

\section{Statistical Analysis}

Values were expressed as means \pm standard deviations, and data were analyzed by one-way ANOVA followed by Dunnett's test using SPSS version 23 (SPSS Inc., Chicago, IL, United States) to determine the significances of differences. Statistical significance was accepted for $p$-values of $<0.05$.

TABLE 1 | Herring oil - GC-MS analysis.

\begin{tabular}{|c|c|c|}
\hline Lipid number & Fatty acid name & Composition (\%) \\
\hline C12:0 & Lauric acid & 0.13 \\
\hline C13:0 & Tridecanoic acid & 0.03 \\
\hline C14:0 & Myristic acid & 5.78 \\
\hline C14:1 & Tetradecenoic & 0.05 \\
\hline C15:0 & Pentadecanoic acid & 0.45 \\
\hline C16:0 & Palmitic acid & 8.18 \\
\hline C16:1 & Palmitoleic acid & 2.15 \\
\hline $\mathrm{C} 17: 0$ & Heptadecanoic acid & 0.36 \\
\hline $\mathrm{C} 17: 1$ & cis-10-Heptadecenoic aid & 0.05 \\
\hline C18:0 & Stearic acid & 1.35 \\
\hline C18:1n-9,trans & Elaidic acid & 0.09 \\
\hline C18:1n-9,cis & Oleic acid & 2.72 \\
\hline C18:2n-6,cis & Linoleic acid & 1.11 \\
\hline C18:3n-6 & $\gamma$-Linolenic acid & 0.20 \\
\hline C20:1 & cis-11-Eicosenoic acid & 9.75 \\
\hline C18:3n-3 & $\alpha$-Linolenic acid & 1.23 \\
\hline $\mathrm{C} 21: 0$ & Heneicosanoic acid & 0.22 \\
\hline C20:2n-6 & Eicosadienoic acid & 3.80 \\
\hline C22:0 & Behenic acid & 0.05 \\
\hline C20:3n-6 & Dihomo- $\gamma$-Linolenic acid & 0.07 \\
\hline C22:1n-9 & Erucic acid & 17.49 \\
\hline C20:3n-3 & $\begin{array}{l}\text { cis-11,14,17-Eicosatrienoic } \\
\text { acid }\end{array}$ & 0.1 \\
\hline $\mathrm{C} 23: 0$ & Tricosanoic acid & 0.24 \\
\hline C22:2 & Docosadienoic acid & 0.91 \\
\hline $\mathrm{C} 24: 0$ & Lignoceric acid & 0.02 \\
\hline C20:5n-3 & $\begin{array}{l}\text { cis-5,8,11,14,17- } \\
\text { Eicosapentaenoic acid } \\
\text { (EPA) }\end{array}$ & 5.78 \\
\hline $\mathrm{C} 24: 1$ & Nervonic acid & 0.93 \\
\hline C22:6n-3 & $\begin{array}{l}\text { cis-4,7,10,13,16,19- } \\
\text { Docosahexaenoic acid } \\
\text { (DHA) }\end{array}$ & 11.31 \\
\hline
\end{tabular}

Components present at levels $>5 \%$ by weight are shown in blue/bold font. 


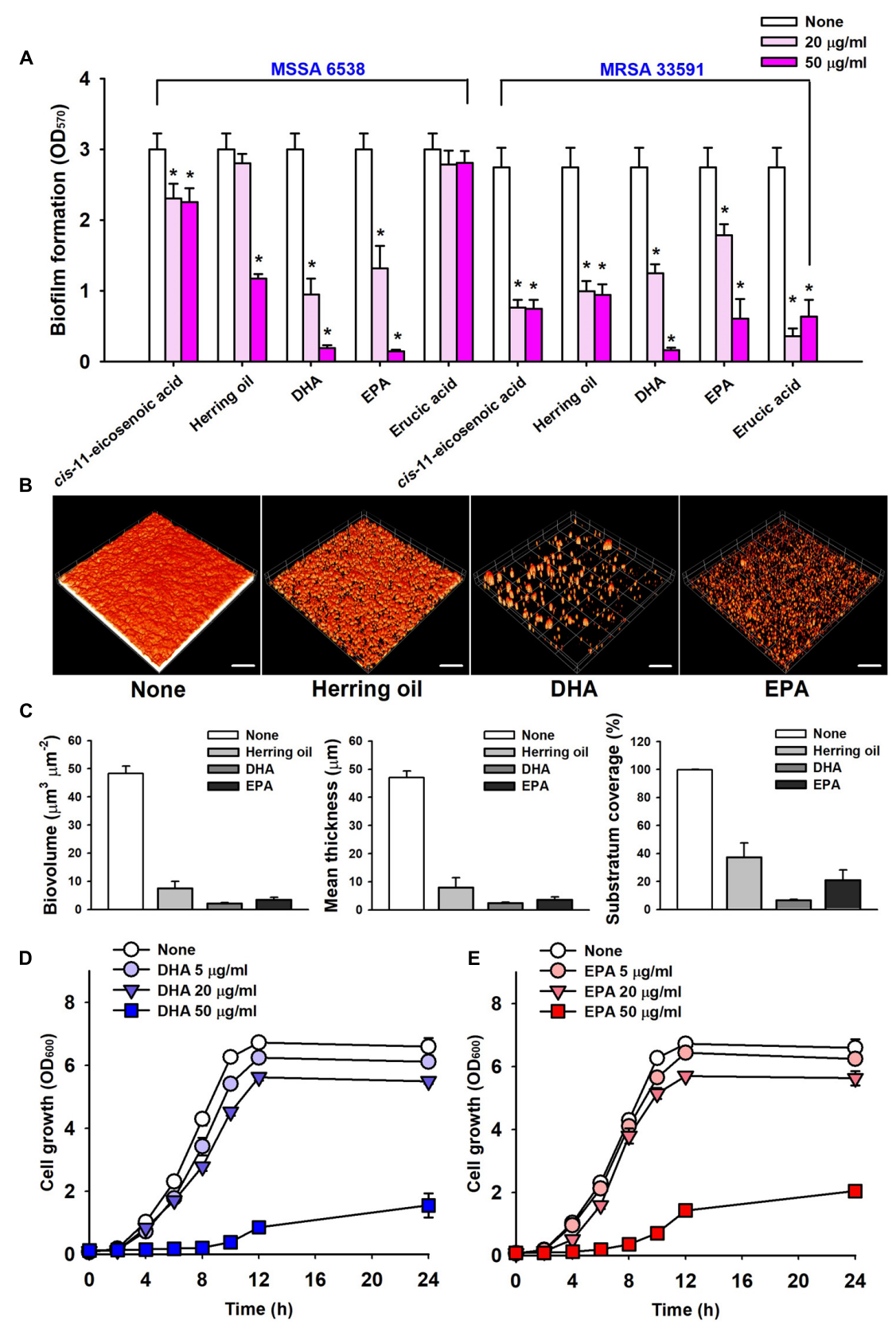

FIGURE 2 | Inhibitions of biofilm formation by herring oil, DHA, and EPA. Biofilm formations by the two S. aureus strains were quantified in the presence of cis-11-eicosenoic acid, herring oil, DHA, EPA, and erucic acid at 20 or $50 \mu \mathrm{g} / \mathrm{ml}$ after incubation for $24 \mathrm{~h}$ in 96-well polystyrene plates without agitation (A). Biofilm

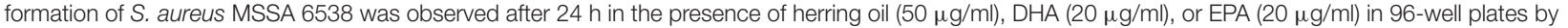
confocal laser scanning microscopy (B). The scale bars represent $100 \mu \mathrm{m}$. Biofilm formation was analyzed using COMSTAT (C). Cell growth of S. aureus MSSA 6538 was measured in the presence of DHA or EPA (D,E). ${ }^{*} p<0.05$ vs. non-treated controls.

\section{RESULTS AND DISCUSSION}

\section{Effect of Herring Oil on S. aureus Biofilm Formation}

The anti-biofilm activity of herring oil was investigated against two S. aureus strains (MSSA 6538 and MRSA 33591) in 96-well polystyrene plates. The addition of herring oil at the beginning of bacterial culture dose-dependently inhibited $S$. aureus biofilm formation (Figures 1A,B). Specifically, herring oil at $100 \mu \mathrm{g} / \mathrm{ml}$ reduced biofilm formation by MSSA 6538 by $>75 \%$, whereas $20 \mu \mathrm{g} / \mathrm{ml}$ was required to inhibit biofilm formation by MRSA 33591 by $>65 \%$.

Herring oil did not decrease the growth of $S$. aureus strains (MSSA 6538 and MRSA 33591) at concentrations up 

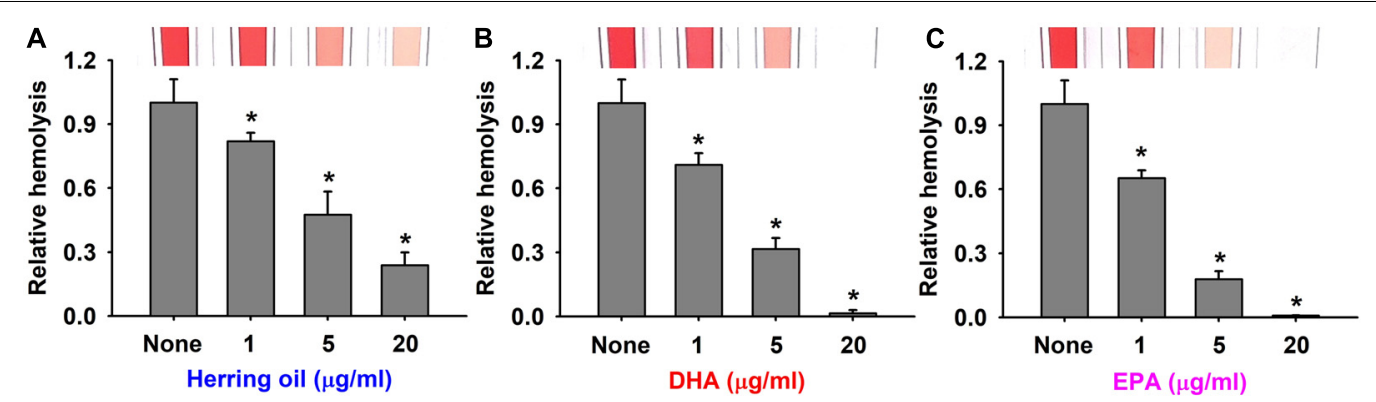

FIGURE 3 | Anti-hemolytic activities of herring oil, DHA, and EPA. Human red blood cell hemolysis by S. aureus was investigated in the presence of herring oil (A), DHA (B), or EPA (C) after culture for $20 \mathrm{~h}$. The images show hemolysis activities in spectrophotometer cuvettes. ${ }^{*} p<0.05$ vs. non-treated controls.

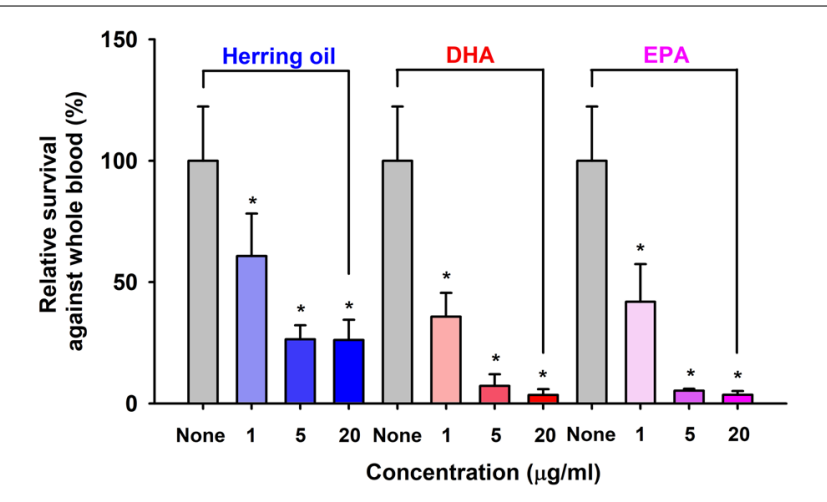

FIGURE 4 | Killing of $S$. aureus by whole blood cells in the presence of herring oil, DHA, or EPA. S. aureus cells were cultured in the presence of herring oil, $\mathrm{DHA}$, or EPA at 1,5 , and $20 \mu \mathrm{g} / \mathrm{ml}$ for $20 \mathrm{~h}$, then mixed with freshly drawn human whole blood and cultured for $3 \mathrm{~h}$. Percent survival of $S$. aureus treated with or without the test compounds is represented. ${ }^{*} p<0.05$ vs. non-treated controls.

to $1000 \mu \mathrm{g} / \mathrm{ml}$ (Figures $\mathbf{1 C}, \mathbf{D}$ ), and did not affect planktonic cell numbers of either $S$. aureus strain at concentrations up to $1000 \mu \mathrm{g} / \mathrm{ml}$ (data not shown). These findings show the antibiofilm activity of herring oil was not due to any bactericidal effects.

\section{Identification of Main Components in Herring Oil}

Gas chromatography-mass spectrometry identified 28 fatty acids in herring oil (Table 1). Components that constituted more than $5 \%$ of herring oil were; erucic acid (17.49\%), cis-4,7,10,13,16,19DHA (11.31\%), cis-11-eicosenoic acid (9.75\%), palmitic acid (8.18\%), myristic acid (5.78\%), and cis-5,8,11,14,17-EPA (5.78\%) (Table 1). The compositions of herring oil identified by GCMS analysis concur with previous studies (Lambertsen and Braekkan, 1965). Previously, unsaturated fatty acids, such as, cis-11-eicosenoic acid and oleic acid showed strong anti-biofilm effect while saturated fatty acids (myristic acid and palmitic acid) did not have anti-biofilm activity against $S$. aureus (Lee et al., 2017). Therefore, this study was focused on the anti-biofilm activities of three unsaturated predominant omega fatty acids (DHA, EPA, and erucic acid).

\section{Effect of DHA and EPA on Biofilm Formation by $S$. aureus}

The anti-biofilm potencies of four major PUFAs (cis-11eicosenoic acid, DHA, EPA, and erucic acid) were tested against the two S. aureus strains (MSSA 6538 and MRSA 33591) in 96-well plates. cis-11-Eicosenoic acid, DHA, and EPA at concentrations of $20 \mu \mathrm{g} / \mathrm{ml}$ significantly inhibited biofilm formation by both $S$. aureus strains (Figure 2A). DHA and EPA both inhibited biofilm formation by $>90 \%$ at $50 \mu \mathrm{g} / \mathrm{ml}$, which was greater than that previously reported for cis-11eicosenoic acid (Lee et al., 2017). In this previous report, relationships between free fatty acids and bacterial biofilm formation were studied. In particular, oleic acid and cis-2decenoic acid were found to suppress biofilm formation of $S$. aureus by blocking bacterial adhesion and dispersion from established biofilms, respectively (Stenz et al., 2008; Davies and Marques, 2009). In addition, it has been suggested that long chain unsaturated fatty acids like cis-11-eicosenoic acid (Lee et al., 2017) inhibit the biofilm forming ability of S. aureus. However, the present study is the first to report the antibiofilm activities of DHA and EPA against $S$. aureus. The unsaturated fatty acid erucic acid, which was present in herring oil at high levels (Table 1), at $20 \mu \mathrm{g} / \mathrm{ml}$ inhibited biofilm formation by MRSA 33591 by $>85 \%$, but did not inhibit biofilm formation by MSSA 6538 (Figure 2A). However, higher concentrations of erucic acid at 500 and $1000 \mu \mathrm{g} / \mathrm{ml}$ significantly reduced biofilm formation of MSSA 6538 without affecting planktonic growth (data not shown). Hence, it appears that the effects of erucic acid are dose-dependent and strain dependent.

Confocal laser scanning microscopy was used to quantify biofilm formation by $S$. aureus in the presence of herring oil, DHA, or EPA. Fluorescent stacking 3D images indicated that herring oil $(50 \mu \mathrm{g} / \mathrm{ml})$, DHA $(20 \mu \mathrm{g} / \mathrm{ml})$, or EPA (20 $\mu \mathrm{g} / \mathrm{ml}$ ) markedly inhibited $S$. aureus biofilm formation (Figure 2B), and this, was confirmed by COMSTAT. More specifically, DHA, EPA, and herring oil reduced all three S. aureus MSSA 6538 parameters measured (biovolume, mean 

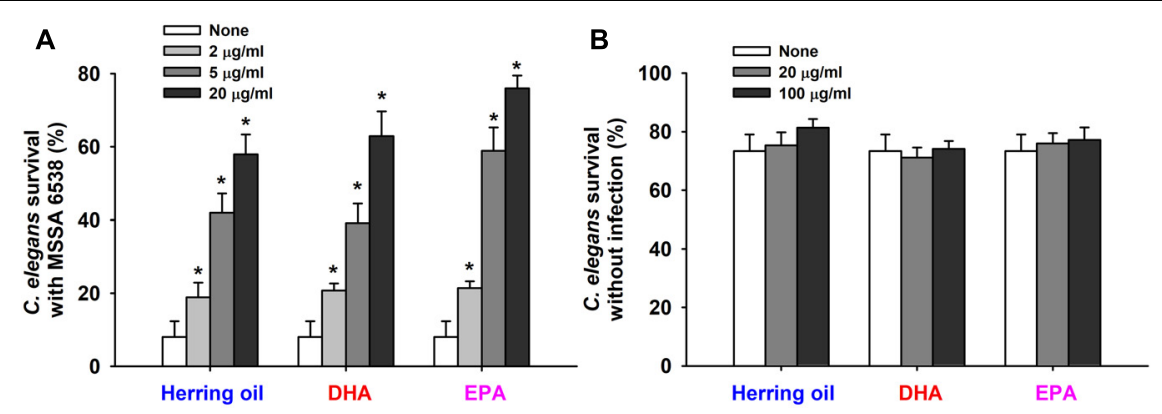

FIGURE 5 | Effects of herring oil, DHA, and EPA on nematode survival. C. elegans fer-15;fem-1 strain survival after infection with S. aureus MSSA 6538 in the presence of DHA, EPA, or herring oil $(2,5$, or $20 \mu \mathrm{g} / \mathrm{ml})$ after exposure for 1 day at $25^{\circ} \mathrm{C}(\mathbf{A})$. Herring oil, DHA, and EPA toxicities were assessed by determining survival rates versus non-infected nematodes (B). Survival was assessed as dead or alive based on movement. ${ }^{*} p<0.05$ versus non-treated controls.

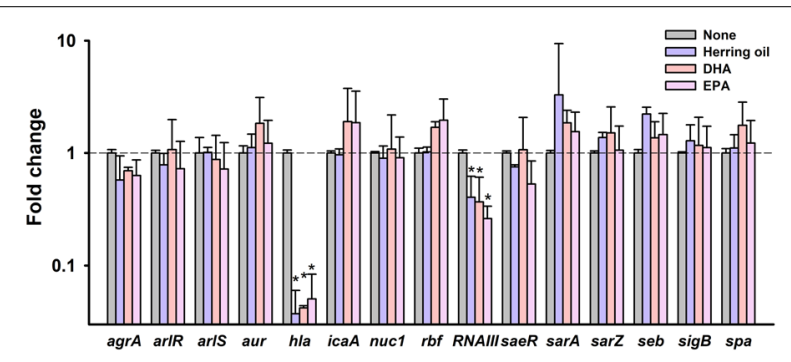

FIGURE 6 | Transcriptional profile changes in S. aureus after treatment with herring oil, DHA, or EPA. S. aureus MSSA 6538 was incubated in LB broth containing herring oil $(100 \mu \mathrm{g} / \mathrm{ml})$, DHA, or EPA $(20 \mu \mathrm{g} / \mathrm{ml})$ for $5 \mathrm{~h}$ with agitation at $250 \mathrm{rpm}$. Relative transcriptional profiles were determined by qRT-PCR with respect to 16 s rRNA expression. qRT-PCR was performed in duplicate and fold-changes were calculated using treated versus untreated S. aureus. ${ }^{*} p<0.05$ vs. non-treated controls.

thickness, and substratum coverage) (Figure 2C), actually, DHA and EPA reduced biomass and mean thickness by $>90 \%$, respectively. These results show herring oil, DHA, and EPA all effectively reduced biofilm formation on the bottom of 96-well plate.

Mature biofilm detachment by antibiotics, enzymes, and fatty acids is interest due to their resistance to antimicrobial agents (Flemming and Wingender, 2010; Gwisai et al., 2017; Lee et al., 2018). However, herring oil $(1000 \mu \mathrm{g} / \mathrm{ml})$, DHA $(100 \mu \mathrm{g} / \mathrm{ml})$, and EPA $(100 \mu \mathrm{g} / \mathrm{ml})$ could not disperse matured S. aureus ATCC 6538 biofilms (data not shown).

\section{Anti-microbial Effects of DHA and EPA on S. aureus}

The anti-microbial activities of DHA and EPA were evaluated by determining their minimum inhibitory concentrations (MICs) against S. aureus MSSA 6538 and MRSA 33591. Planktonic growth was completely inhibited by DHA and EPA at MICs $(200 \mu \mathrm{g} / \mathrm{ml})$, while MICs of ciprofloxacin and vancomycin are $0.5-1 \mu \mathrm{g} / \mathrm{ml}$ and $4 \mu \mathrm{g} / \mathrm{ml}$, respectively, which concurs with previously reported values (Desbois and Lawlor, 2013; Gwisai et al., 2017). Notably, these MICs of DHA and EPA were 10 times higher than the concentration $(20 \mu \mathrm{g} / \mathrm{ml})$ required for anti-biofilm activities (Figure 2A).

Planktonic cell growths of $S$. aureus MSSA 6538 and MRSA 33591 in the presence of $5 \mu \mathrm{g} / \mathrm{ml}$ DHA or $20 \mu \mathrm{g} / \mathrm{ml}$ EPA were slightly inhibited (Figures 2D,E). However, the cell growths of both strains were more than $68 \%$ suppressed by DHA or EPA at $50 \mu \mathrm{g} / \mathrm{ml}$, which indicates both DHA and EPA have anti-bacterial effects at relatively high concentrations (Figures 2D,E). These observations suggest DHA and EPA at low concentrations have anti-biofilm effects, but at higher levels these can also suppress the growth of planktonic cells.

\section{Effects of Herring Oil, DHA, and EPA on Hemolysis by $S$. aureus}

Staphylococcus aureus produces $\alpha$-toxin, which is one of the most investigated $S$. aureus cytotoxins. $\alpha$-Toxin integrates into the membranes of erythrocytes causing hemolysis (Bhakdi et al., 1984; Song et al., 1996), which contributes to biofilm formation (Caiazza and O'Toole, 2003). Thus, the effects of herring oil, DHA, and EPA on human red blood cell hemolysis by $S$. aureus were investigated. As a control, herring oil, DHA, and EPA without $S$. aureus cells did not show any hemolytic activity (data not shown). Interestingly, all three dose-dependently inhibited the hemolytic activity of $S$. aureus (Figure 3), and DHA and EPA at $20 \mu \mathrm{g} / \mathrm{ml}$ completely abolished its hemolytic activity, whereas herring oil at $20 \mu \mathrm{g} / \mathrm{ml}$ reduced its hemolytic activity by $>75 \%$. Also, herring oil, DHA, and EPA all significantly reduced the hemolytic activity by $S$. aureus even at $1 \mu \mathrm{g} / \mathrm{ml}$, which is much lower than the concentrations required for anti-biofilm and antimicrobial activities.

These results support that the inhibitions of $S$. aureus biofilm formation by herring oil, DHA, and EPA are associated with the inhibition of hemolysis, and suggest that the genes related to biofilm formation and hemolysis might be responsible for these events. The present study is the first to report that herring oil, DHA, and EPA suppress the hemolysis of human red blood cells by $S$. aureus, which has important implications regarding the control of $S$. aureus virulence. 


\section{Effects of DHA, EPA, and Herring Oil on $S$. aureus Survival in the Presence of Human Whole Blood}

Staphylococcus aureus characteristically exhibits resistance to phagocytes in humans and other animals, and thus, we used a survival test to investigate the effects of herring oil, DHA, and EPA on S. aureus survival in the presence of human whole blood. Herring oil, DHA, or EPA at 1,5 , or $20 \mu \mathrm{g} / \mathrm{ml}$ significantly reduced the survival of $S$. aureus exposed to fresh human whole blood (Figure 4), indicating that they weaken the ability of $S$. aureus to resist the human innate immune system.

\section{Effects of DHA, EPA, and Herring Oil on $S$. aureus Virulence in the Nematode Model}

Staphylococcus aureus colonizes and replicates in the digestive tract of C. elegans and has the ability to kill C. elegans by an infection-like process that exhibits remarkable overlap with that observed in mammals (Garsin et al., 2003). Hence, the effects of herring oil, DHA, and EPA on S. aureus virulence were investigated by analyzing $C$. elegans survival in the presence of $S$. aureus. Herring oil, DHA, and EPA were found to markedly prolong $C$. elegans survival in the presence of $S$. aureus (Figure 5A). For example, nematode survival was only $\sim 10 \%$ in the presence of untreated $S$. aureus, whereas in the presence of herring oil, DHA, or EPA at $20 \mu \mathrm{g} / \mathrm{ml}$ more than 55, 60, and $70 \%$, respectively, of worms survived. In other words, the survival rate of C. elegans was increased more than seven and ninefold when worms were exposed to $S$. aureus in the presence of DHA or EPA at $20 \mu \mathrm{g} / \mathrm{ml}$, respectively (Figure 5A). In addition, no toxic effects were observed when non-infected worms were exposed to herring oil, DHA, or EPA at concentrations up to $100 \mu \mathrm{g} / \mathrm{ml}$ (Figure 5B).

\section{Transcriptional Changes Induced by DHA, EPA, and by Herring Oil in S. aureus}

To investigate the molecular mechanisms underlying the inhibitory effects of herring oil, DHA, and EPA against $S$. aureus, expressions of selected biofilm- and virulence-related genes, and important regulatory genes were investigated in S. aureus cells by qRT-PCR. Herring oil, DHA, and EPA dramatically reduced the expression of $\alpha$-hemolysin (hla) by 27-, 24-, and 20-fold, respectively (Figure 6). Also, herring oil, DHA, and EPA downregulated regulatory RNA molecule (RNAIII) that is present upstream of the agr operon while the expressions of other genes were not affected (Figure 6). It has been reported that RNAIII stimulate hla translation (Morfeldt et al., 1995). Hence, hla repression is partially due to the down-regulation of RNAIII by herring oil, DHA, and EPA.

$\alpha$-Hemolysin is known to play a critical role in cell-to-cell interactions during biofilm formation (Caiazza and O'Toole, 2003; Anderson et al., 2012; Scherr et al., 2015). This reduction of $\alpha$-hemolysin expression has been discovered in recently published articles showing that alizarin (Lee et al., 2016), azithromycin (Gui et al., 2014), flavonoids (Cho et al., 2015), norlichexanthone (Baldry et al., 2016), and stilbenoids (Lee et al., 2014) inhibit both biofilm formation and hemolysis by $S$. aureus. Our findings support that $\alpha$-hemolysin has a positive relationship with biofilm formation in $S$. aureus. In addition, it has been shown hla is essential for $S$. aureus pathogenicity in a nematode model (Sifri et al., 2003, 2006). Notably, neither herring oil, DHA, or EPA significantly affected the expressions of the biofilm-related genes namely, agrA, arlR, arls, aur, $i c a A, n u c 1, \operatorname{rbf}, \operatorname{sae}$, sarA, sarZ, seb, sigB, or spa. Thus, the present study indicates that herring oil, DHA, and EPA attenuate $S$. aureus virulence, as evidenced by reductions in its antibiofilm (Figures 1, 2) and anti-hemolytic (Figure 3) activities, and partially by down-regulating the expression of the hla gene (Figure 6).

These results indicate that herring oil, DHA, and EPA could be used to treat $S$. aureus infections as lone drug or in combination with traditional antibiotics (Figure 5). Furthermore, because all three are considered intrinsically safe in animal, they could be used for medicinal purposes or for example, to surface treat in food processing facilities without undue restriction.

\section{CONCLUSION}

The DHA and EPA are long chain omega-3 fatty acids, which have major health benefits in man. More specifically, circulating levels of DHA and EPA are essential part of the body's defense system and play key roles in the inhibitions of inflammation and host immune responses (Calder, 2013). Herring oil was found to contain DHA and EPA at levels of 11.3 and $5.8 \%$ by weight, respectively, and inhibit biofilm formation and hemolysis by and the virulence of $S$. aureus. Interestingly, the ability of $S$. aureus to survive exposure to human whole blood was reduced in the presence of DHA or EPA, and exposure to DHA or EPA also increased infected nematode survival. These findings show for the first time that DHA and EPA suppress $S$. aureus biofilm formation and its virulence. Also, herring oil and its constituent omega-3 fatty acids (DHA and EPA) might be useful for the treatment and/or prevention of surface-associated biofilm formation by $S$. aureus (including MRSA strains) and for suppressing its virulence.

\section{AUTHOR CONTRIBUTIONS}

Y-GK, J-HL, CR, and SO performed the experiments and analyzed the data. Y-GK, J-HL, JP, and JL designed the study and wrote the paper. All authors read and approved the final manuscript.

\section{FUNDING}

This research was conducted under the industrial infrastructure program for fundamental technologies (N0000885) which is funded by the Ministry of Trade, Industry and Energy (MOTIE, South Korea). This research was also supported 
by the Basic Science Research Program of a National Research Foundation of Korea (NRF) funded by the Korean Ministry of Education (2018R1D1A3B07040699 to J-HL) and (2017R1A6A3A01076089 to Y-GK), and a Priority Research Centers Program (\#2014R1A6A1031189).

\section{REFERENCES}

Anderson, M. J., Lin, Y. C., Gillman, A. N., Parks, P. J., Schlievert, P. M., and Peterson, M. L. (2012). Alpha-toxin promotes Staphylococcus aureus mucosal biofilm formation. Front. Cell. Infect. Microbiol. 2:64. doi: 10.3389/fcimb.2012. 00064

Baldry, M., Nielsen, A., Bojer, M. S., Zhao, Y., Friberg, C., Ifrah, D., et al. (2016). Norlichexanthone reduces virulence gene expression and biofilm formation in Staphylococcus aureus. PLoS One 11:e0168305. doi: 10.1371/journal.pone. 0168305

Bhakdi, S., Muhly, M., and Fussle, R. (1984). Correlation between toxin binding and hemolytic activity in membrane damage by staphylococcal alpha-toxin. Infect. Immun. 46, 318-323.

Bougnoux, P. (1999). n-3 polyunsaturated fatty acids and cancer. Curr. Opin. Clin. Nutr. Metab. Care 2, 121-126. doi: 10.1097/00075197-199903000-00005

Caiazza, N. C., and O'Toole, G. A. (2003). Alpha-toxin is required for biofilm formation by Staphylococcus aureus. J. Bacteriol. 185, 3214-3217. doi: 10.1128/ JB.185.10.3214-3217.2003

Calder, P. C. (2013). Omega-3 polyunsaturated fatty acids and inflammatory processes: nutrition or pharmacology? Br. J. Clin. Pharmacol. 75, 645-662. doi: 10.1111/j.1365-2125.2012.04374.x

Chambers, H. F., and Deleo, F. R. (2009). Waves of resistance: Staphylococcus aureus in the antibiotic era. Nat. Rev. Microbiol. 7, 629-641. doi: 10.1038/ nrmicro2200

Cho, H. S., Lee, J.-H., Cho, M. H., and Lee, J. (2015). Red wines and flavonoids diminish Staphylococcus aureus virulence with anti-biofilm and anti-hemolytic activities. Biofouling 31, 1-11. doi: 10.1080/08927014.2014. 991319

Correia, M., Michel, V., Matos, A. A., Carvalho, P., Oliveira, M. J., Ferreira, R. M., et al. (2012). Docosahexaenoic acid inhibits Helicobacter pylori growth in vitro and mice gastric mucosa colonization. PLoS One 7:e35072. doi: 10.1371/journal. pone. 0035072

Davies, D. G., and Marques, C. N. (2009). A fatty acid messenger is responsible for inducing dispersion in microbial biofilms. J. Bacteriol. 191, 1393-1403. doi: 10.1128/JB.01214-08

Desbois, A. P., and Lawlor, K. C. (2013). Antibacterial activity of long-chain polyunsaturated fatty acids against Propionibacterium acnes and Staphylococcus aureus. Mar. Drugs. 11, 4544-4557. doi: 10.3390/md11114544

Desbois, A. P., Mearns-Spragg, A., and Smith, V. J. (2009). A fatty acid from the diatom Phaeodactylum tricornutum is antibacterial against diverse bacteria including multi-resistant Staphylococcus aureus (MRSA). Mar. Biotechnol. 11, 45-52. doi: 10.1007/s10126-008-9118-5

Flemming, H. C., and Wingender, J. (2010). The biofilm matrix. Nat. Rev. Microbiol. 8, 623-633. doi: 10.1038/nrmicro2415

Garsin, D. A., Villanueva, J. M., Begun, J., Kim, D. H., Sifri, C. D., Calderwood, S. B., et al. (2003). Long-lived C. elegans daf-2 mutants are resistant to bacterial pathogens. Science 300, 1921-1921. doi: 10.1126/science.1080147

Giordano, E., and Visioli, F. (2014). Long-chain omega 3 fatty acids: molecular bases of potential antioxidant actions. Prostaglandins Leukot. Essent. Fatty Acids 90, 1-4. doi: 10.1016/j.plefa.2013.11.002

Gui, Z., Wang, H., Ding, T., Zhu, W., Zhuang, X., and Chu, W. (2014). Azithromycin reduces the production of alpha-hemolysin and biofilm formation in Staphylococcus aureus. Indian J. Microbiol. 54, 114-117. doi: 10.1007/s12088-013-0438-4

Gwisai, T., Hollingsworth, N. R., Cowles, S., Tharmalingam, N., Mylonakis, E., Fuchs, B. B., et al. (2017). Repurposing niclosamide as a versatile antimicrobial surface coating against device-associated, hospital-acquired bacterial infections. Biomed. Mater. 12:045010. doi: 10.1088/1748-605X/aa7105

Heydorn, A., Nielsen, A. T., Hentzer, M., Sternberg, C., Givskov, M., Ersboll, B. K., et al. (2000). Quantification of biofilm structures by the novel computer

\section{SUPPLEMENTARY MATERIAL}

The Supplementary Material for this article can be found online at: https://www.frontiersin.org/articles/10.3389/fmicb. 2018.01241/full\#supplementary-material

program COMSTAT. Microbiology 146, 2395-2407. doi: 10.1099/00221287146-10-2395

Hirai, A., Hamazaki, T., Terano, T., Nishikawa, T., Tamura, Y., Kamugai, A., et al. (1980). Eicosapentaenoic acid and platelet function in Japanese. Lancet 2, 1132-1133. doi: 10.1016/S0140-6736(80)92558-1

Hoffman, L. R., D’Argenio, D. A., MacCoss, M. J., Zhang, Z., Jones, R. A., and Miller, S. I. (2005). Aminoglycoside antibiotics induce bacterial biofilm formation. Nature 436, 1171-1175. doi: 10.1038/nature03912

Huang, C. B., and Ebersole, J. L. (2010). A novel bioactivity of omega-3 polyunsaturated fatty acids and their ester derivatives. Mol. Oral Microbiol. 25, 75-80. doi: 10.1111/j.2041-1014.2009.00553.x

Kang, H.-S., Jeong, S.-W., Ko, J.-C., Jang, M., and Kim, J.-C. (2011). The quality characteristics of commercial gwamegi by product types. J. Food Sci. Nutr. 16, 253-260. doi: 10.3746/jfn.2011.16.3.253

Kim, Y.-G., Lee, J.-H., Gwon, G., Kim, S.-I., Park, J. G., and Lee, J. (2016). Essential oils and eugenols inhibit biofilm formation and the virulence of Escherichia coli O157:H7. Sci. Rep. 6:36377. doi: 10.1038/srep36377

Kim, Y.-G., Lee, J.-H., Kim, S.-I., Baek, K.-H., and Lee, J. (2015). Cinnamon bark oil and its components inhibit biofilm formation and toxin production. Int. J. Food Microbiol. 195, 30-39. doi: 10.1016/j.ijfoodmicro.2014.11.028

Lambertsen, G., and Braekkan, O. R. (1965). The fatty acid composition of herring oils. Fiskeridirektoratets skrifter Ser. Teknol. Undersøkelser 4, 13.

Lee, J.-H., Kim, Y.-G., and Lee, J. (2018). Thermostable xylanase inhibits and disassembles Pseudomonas aeruginosa biofilms. Biofouling 34, 346-356. doi: 10.1080/08927014.2018.1440551

Lee, J.-H., Kim, Y.-G., Park, J. G., and Lee, J. (2017). Supercritical fluid extracts of Moringa oleifera and their unsaturated fatty acid components inhibit biofilm formation by Staphylococcus aureus. Food Control 80, 74-82. doi: 10.1016/j. foodcont.2017.04.035

Lee, J.-H., Kim, Y.-G., Ryu, S. Y., and Lee, J. (2016). Calcium-chelating alizarin and other anthraquinones inhibit biofilm formation and the hemolytic activity of Staphylococcus aureus. Sci. Rep. 6:19267. doi: 10.1038/srep19267

Lee, J.-H., Park, J.-H., Cho, H. S., Joo, S. W., Cho, M. H., and Lee, J. (2013). Antibiofilm activities of quercetin and tannic acid against Staphylococcus aureus. Biofouling 29, 491-499. doi: 10.1080/08927014.2013.788692

Lee, K., Lee, J.-H., Ryu, S. Y., Cho, M. H., and Lee, J. (2014). Stilbenes reduce Staphylococcus aureus hemolysis, biofilm formation, and virulence. Foodborne Pathog. Dis. 11, 710-717. doi: 10.1089/fpd.2014.1758

Lee, J.-W., Cho, K.-H., Yook, H.-S., Jo, C., Kim, D.-H., and Byun, M.-W. (2002). The effect of gamma irradiation on the stability and hygienic quality of semidried pacific saury (Cololabis seira) flesh. Radiat. Phys. Chem. 64, 309-315. doi: 10.1016/S0969-806X(01)00675-2

Liu, C. I., Liu, G. Y., Song, Y., Yin, F., Hensler, M. E., Jeng, W. Y., et al. (2008). A cholesterol biosynthesis inhibitor blocks Staphylococcus aureus virulence. Science 319, 1391-1394. doi: 10.1126/science.1153018

Lowy, F. D. (1998). Staphylococcus aureus infections. N. Engl. J. Med. 339, 520-532. doi: 10.1056/NEJM199808203390806

Menzies, B. E., and Kernodle, D. S. (1996). Passive immunization with antiserum to a nontoxic alpha-toxin mutant from Staphylococcus aureus is protective in a murine model. Infect. Immun. 64, 1839-1841.

Mil-Homens, D., Bernardes, N., and Fialho, A. M. (2012). The antibacterial properties of docosahexaenoic omega-3 fatty acid against the cystic fibrosis multiresistant pathogen Burkholderia cenocepacia. FEMS Microbiol. Lett. 328, 61-69. doi: 10.1111/j.1574-6968.2011.02476.x

Morfeldt, E., Taylor, D., von Gabain, A., and Arvidson, S. (1995). Activation of alpha-toxin translation in Staphylococcus aureus by the trans-encoded antisense RNA. RNAIII. EMBO J. 14, 4569-4577.

Ohlsen, K., Koller, K. P., and Hacker, J. (1997). Analysis of expression of the alphatoxin gene (hla) of Staphylococcus aureus by using a chromosomally encoded hla::lacZ gene fusion. Infect. Immun. 65, 3606-3614. 
Otto, M. (2014). Staphylococcus aureus toxins. Curr. Opin. Microbiol. 17, 32-37. doi: 10.1016/j.mib.2013.11.004

Potera, C. (1999). Forging a link between biofilms and disease. Science 283, 1837-1839. doi: 10.1126/science.283.5409.1837

Scherr, T. D., Hanke, M. L., Huang, O., James, D. B., Horswill, A. R., Bayles, K. W., et al. (2015). Staphylococcus aureus biofilms induce macrophage dysfunction through leukocidin AB and alpha-toxin. MBio 6, e1021-e1015. doi: 10.1128/ mBio.01021-15

Schmidt, E. B., and Dyerberg, J. (1994). Omega-3 fatty acids. Current status in cardiovascular medicine. Drugs 47, 405-424. doi: 10.2165/00003495199447030-00003

Sifri, C. D., Baresch-Bernal, A., Calderwood, S. B., and von Eiff, C. (2006). Virulence of Staphylococcus aureus small colony variants in the Caenorhabditis elegans infection model. Infect. Immun. 74, 1091-1096. doi: 10.1128/IAI.74.2.10911096.2006

Sifri, C. D., Begun, J., Ausubel, F. M., and Calderwood, S. B. (2003). Caenorhabditis elegans as a model host for Staphylococcus aureus pathogenesis. Infect. Immun. 71, 2208-2217. doi: 10.1128/IAI.71.4.2208-2217.2003

Singhal, D., Foreman, A., Jervis-Bardy, J., and Wormald, P. J. (2011). Staphylococcus aureus biofilms: Nemesis of endoscopic sinus surgery. Laryngoscope 121, 1578-1583. doi: 10.1002/lary.21805

Song, L., Hobaugh, M. R., Shustak, C., Cheley, S., Bayley, H., and Gouaux, J. E. (1996). Structure of staphylococcal $\alpha$-hemolysin, a heptameric transmembrane pore. Science 274, 1859-1866. doi: 10.1126/science.274.5294.1859

Speller, D. C., Johnson, A. P., James, D., Marples, R. R., Charlett, A., and George, R. C. (1997). Resistance to methicillin and other antibiotics in isolates of Staphylococcus aureus from blood and cerebrospinal fluid, England and Wales, 1989-95. Lancet 350, 323-325. doi: 10.1016/S0140-6736(97)12148-1

Stenz, L., Francois, P., Fischer, A., Huyghe, A., Tangomo, M., Hernandez, D., et al. (2008). Impact of oleic acid (cis-9-octadecenoic acid) on bacterial viability and biofilm production in Staphylococcus aureus. FEMS Microbiol. Lett. 287, 149-155. doi: 10.1111/j.1574-6968.2008.01316.x

Stewart, P. S., and Costerton, J. W. (2001). Antibiotic resistance of bacteria in biofilms. Lancet 358, 135-138. doi: 10.1016/S0140-6736(01)05321-1
Sun, M., Dong, J., Xia, Y., and Shu, R. (2017). Antibacterial activities of docosahexaenoic acid (DHA) and eicosapentaenoic acid (EPA) against planktonic and biofilm growing Streptococcus mutans. Microb. Pathog. 107, 212-218. doi: 10.1016/j.micpath.2017.03.040

Sun, M., Zhou, Z., Dong, J., Zhang, J., Xia, Y., and Shu, R. (2016). Antibacterial and antibiofilm activities of docosahexaenoic acid (DHA) and eicosapentaenoic acid (EPA) against periodontopathic bacteria. Microb. Pathog. 99, 196-203. doi: 10.1016/j.micpath.2016.08.025

Tharmalingam, N., Rajmuthiah, R., Kim, W., Fuchs, B. B., Jeyamani, E., Kelso, M. J., et al. (2018). Antibacterial properties of four novel hit compounds from a methicillin-resistant Staphylococcus aureus-Caenorhabditis elegans highthroughput screen. Microb. Drug Resist. doi: 10.1089/mdr.2017.0250 [Epub ahead of print].

Thibane, V. S., Kock, J. L., Ells, R., van Wyk, P. W., and Pohl, C. H. (2010). Effect of marine polyunsaturated fatty acids on biofilm formation of Candida albicans and Candida dubliniensis. Mar. Drugs 8, 2597-2604. doi: 10.3390/md8102597

Van Dyke, T. E. (2008). The management of inflammation in periodontal disease. J. Periodontol. 79, 1601-1608. doi: 10.1902/jop.2008.080173

Wilke, G. A., and Bubeck Wardenburg, J. (2010). Role of a disintegrin and metalloprotease 10 in Staphylococcus aureus $\alpha$-hemolysin-mediated cellular injury. Proc. Natl. Acad. Sci. U.S.A. 107, 13473-13478. doi: 10.1073/pnas. 1001815107

Conflict of Interest Statement: The authors declare that the research was conducted in the absence of any commercial or financial relationships that could be construed as a potential conflict of interest.

Copyright (c) 2018 Kim, Lee, Raorane, Oh, Park and Lee. This is an open-access article distributed under the terms of the Creative Commons Attribution License (CC BY). The use, distribution or reproduction in other forums is permitted, provided the original author(s) and the copyright owner are credited and that the original publication in this journal is cited, in accordance with accepted academic practice. No use, distribution or reproduction is permitted which does not comply with these terms. 